\title{
Obituary Samuel C Kaim
}

Neuropsychopharmacology (2012) 37, 2885; doi: I0.1038/npp.2012.164

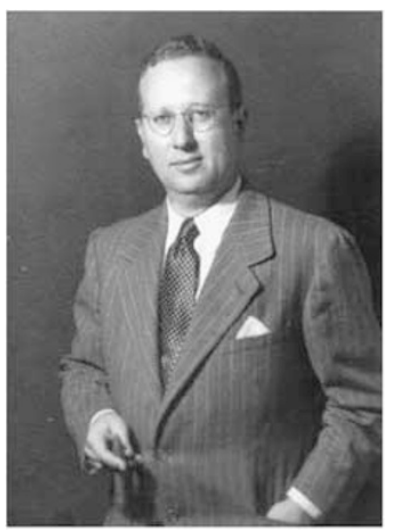

Samuel C Kaim had a long life. He was born in New York City on 24 November 1911 and died on 24 March 2012 in Washington, DC. During this period, he saw and contributed to the birth and enormous growth of our field. His undergraduate training was in Cleveland at Western Reserve (Case Western) and his medical training in Switzerland at the University of Zurich, with a residency there at the Burghölzli Clinic. For his first, direct exposure to psychopharmacology, he was charged with administering insulin and metrazole seizure therapies. With little doubt, the residency had many influences on his later career.

He conducted a private practice for several years in Illinois, interrupted by 4 years as a medical officer during WWII. In 1950, he took what was to be the first of many positions in the VA. First, he headed psychiatry and neurology at the VA Hospital in Coral Gables, Florida. The VA was becoming a major source of clinical trials at the time and Sam participated in these, using EEG techniques, and was among the first to show the profound effects of chlordiazepoxide in reducing or preventing both seizures and delirium tremens in alcohol withdrawal.

In 1960, he went to the central office of the VA to become the head of research nationwide for psychiatry and neurology. He became a strong advocate of VA Cooperative
Studies and decided to use this mechanism to pursue the benefits of chlordiazepoxide in the alcohol withdrawal syndrome, and it became widely recognized as the drug of choice for this use. The VA had been slow to recognize alcoholism as worthy of its own service. After considerable advocacy, Sam became the first director of an Alcoholism Service in the VA. He helped to compel armed forces personnel to recognize the significance of opioid dependence in Vietnam, leading a charge for expansion of his office in 1970 to become the Alcohol and Drug Dependence Services.

Through his VA appointment, Sam had the opportunity to work with Jerome Jaffe when Jerry headed the Special Action Office for Drug Abuse Prevention. Together with their colleagues, they focused on development of the long-acting methadone, $\mathrm{L}-\alpha$-acetyl-methadol (LAAM) for heroin treatment, and on development of naltrexone, the long-acting narcotic antagonist, as a useful agent in heroin addiction. Though it took until 1993 for LAAM to be approved by the FDA, their perseverance had an important role in the survival of these interesting interventions. Certainly, we have yet to discover the final place of naltrexone in medicine.

Sam left the VA in 1975 and became director of staff of the National Academy of Sciences that coordinated one of the pilot studies of naltrexone in the treatment of heroin abuse. He was also a consultant to NIDA in a variety of roles through to the approval of naltrexone for marketing by the FDA. He vigorously continued a variety of activities with professional organizations until he retired in 1993. Those of you who enjoy good collegial conversation will be delighted by the interview conducted by Leo Hollister of the then 85year-old Sam for our History of the ACNP. It illustrates many, many of the interesting characteristics of Sam.

Sam Kaim is survived by his son, Edward, of Weston, Connecticut, and two stepchildren, Judith Plavnick Kiley of Arlington, Virginia, and Jonathan Plavnick of Perry Hall, Maryland.

James Hoods ${ }^{1}$

${ }^{1}$ Department of Pharmacology, University of Michigan Medical School, Ann Arbor, MI, USA E-mail: jhwoods@umich.edu 